\title{
Article \\ Facile Synthesis of MOFs-Templated Carbon Aerogels with Enhanced Tetracycline Adsorption Performance
}

\author{
Yan Kong ${ }^{1}$, Kun Han ${ }^{2}$, Yuan Zhuang ${ }^{1, *}$ and Baoyou Shi ${ }^{1,3}$ \\ 1 Key Laboratory of Drinking Water Science and Technology, Research Center for Eco-Environmental Sciences, \\ Chinese Academy of Sciences, Beijing 100085, China; kongyanmail@163.com (Y.K.); byshi@rcees.ac.cn (B.S.) \\ 2 Chinese Research Academy of Environmental Sciences, Beijing 100012, China; hankunmail@126.com \\ 3 University of Chinese Academy of Sciences, Beijing 100049, China \\ * Correspondence: yuanzhuang@rcees.ac.cn; Tel.: +86-10-62922155
}

check for updates

Citation: Kong, Y.; Han, K.; Zhuang, Y.; Shi, B. Facile Synthesis of MOFs-Templated Carbon Aerogels with Enhanced Tetracycline Adsorption Performance. Water 2022, 14, 504. https://doi.org/10.3390/ w14030504

Academic Editors:

Jesus Gonzalez-Lopez and Alexandre T. Paulino

Received: 21 December 2021

Accepted: 28 January 2022

Published: 8 February 2022

Publisher's Note: MDPI stays neutral with regard to jurisdictional claims in published maps and institutional affiliations.

Copyright: (c) 2022 by the authors. Licensee MDPI, Basel, Switzerland. This article is an open access article distributed under the terms and conditions of the Creative Commons Attribution (CC BY) license (https:// creativecommons.org/licenses/by/ $4.0 /)$.

\begin{abstract}
Three-dimensional aerogels have great potential for antibiotic removal from aqueous solution due to their excellent solution mass transfer channels and special morphology. Herein, the metal ions were bound with alginate to form alginate-Fe, alginate- $\mathrm{Cu}$, and alginate-Fe-Cu hydrogels, then they were used as nucleation sites for metal organic framework (MOF) growth to obtain MAlgs gels, respectively. Considering the aqueous environmental stability of MOFs particles, the alginate and MOF particles in MAlgs aerogels were pyrolyzed as templates to obtain the derived carbon aerogel CMAlgs. The results showed that the adsorption capacity of MAlgs-Fe-Cu aerogel was higher than that of MAlg-Cu and MAlg-Fe aerogels, up to $\sim 130 \mathrm{mg} \cdot \mathrm{g}^{-1}$. The adsorption performance of carbon aerogel CMAlg-Cu decreased obviously because of the decrease of pore size and oxygencontaining functional groups. The adsorption process is a combination of physical adsorption and chemical adsorption. In addition, CMAlgs aerogels exhibit better recyclability than MAlgs aerogels. This work provides a new strategy for fabricating MOFs-templated in-situ grown carbon aerogels for water purification.
\end{abstract}

Keywords: alginate; aerogel; adsorption; tetracycline

\section{Introduction}

As a broad-spectrum antibiotic, tetracycline is widely used in human health care and animal feed additives because of its low cost and good inhibition and killing effect on many pathogens [1,2]. Antibiotics enter wastewater treatment plants in various forms as persistent substances due to their low metabolic rate and low biodegradation [3,4]. The presence and concentration enrichment of tetracycline in the aquatic environment can cause the enhancement and spread of tetracycline-resistant bacteria and resistance genes, even posing a potential risk to the ecosystem and human health [5-7]. The advanced treatment techniques include adsorption, flocculation, advanced oxidation technology, chemical degradation, and biological treatment [8-11]. Among them, the adsorption separation method is widely used to remove antibiotic contaminants because of its low cost and easy operation [12,13]. Therefore, developing efficient and inexpensive adsorption materials is the key to practical applications. The antibiotics adsorption materials mainly include carbon materials, clay minerals, resins, metal oxides, and metal-organic frameworks [14-16]. However, there are some problems such as low adsorption capacity, difficulty recycling and reusing powder materials, and possible secondary pollution. Research and development of new efficient and inexpensive adsorbent materials is the key to practical applications.

Three-dimensional polymer aerogels have attracted extensive attention in the field of water treatment because of their excellent biodegradability, non-toxicity, easy functionalization and solid-liquid separation properties $[17,18]$. Sodium alginate is an anionic polysaccharide extracted from seaweed, and it has abundant oxygen-containing functional groups [19-23]. Alginic acid has good gel properties and chelates metal ions $\left(\mathrm{Fe}^{3+}\right.$, 
$\mathrm{Al}^{3+}, \mathrm{Cu}^{2+}, \mathrm{Zn}^{2+}, \mathrm{Co}^{2+}$, etc.) to form a hydrogel with an open lattice network. The three-dimensional spatial network structure of the hydrogel provides an effective binding site for the introduction of some functional nanomaterials and can also inhibit the agglomeration of nanomaterials, which is a good encapsulation carrier material [24-30].

MOFs are a class of coordination polymers consisting of two- and three-dimensional network topologies composed of metal ions and organic linkers [31,32]. They are regarded as promising candidate materials for water treatment and purification due to their large specific surface, high porosity, abundant active sites, and size controllability [33-35]. Wang et al. [36] reported that the Mn-doped UiO-66 adsorbent has a maximum adsorption capacity of $184.49 \mathrm{mg} \cdot \mathrm{g}^{-1}$ for tetracycline, which is mainly controlled by $\pi-\pi$ and hydrogen bond interactions. Tian et al. [37] reported that the tetracycline adsorption capacity of NH2-MIL-101(Cr) with mesoporous structure for tetracycline reached 36.15 and $48.80 \%$ in $10 \mathrm{~min}$ and $240 \mathrm{~min}$, respectively. Xia et al. reported that the adsorption of antibiotics on the UiO-66 adsorbent can quickly reach the adsorption equilibrium within $40 \mathrm{~min}$. The adsorption process is mainly dominated by $\pi-\pi$ interaction and the pore structure is larger than the tetracycline molecule [38]. However, MOF adsorbents in water treatment still suffer from the critical problems like poor water stability, difficult recovery, and easy aggregation. Considering the aqueous environmental stability of MOFs particles, there is still a need to explore MOFs-templated adsorbent materials with high adsorption and stability.

This paper reports an easy-to-synthesize MOFs-functionalized aerogel (MAlgs) and MOFs-derived carbon aerogel (CMAlgs) for tetracycline adsorption removal. The adsorption properties of MAlgs and CMAlgs aerogels were investigated by varying the central metal ions within the MOFs particles. Adsorption kinetics and adsorption isotherms were studied to investigate the adsorption process. The physicochemical properties of MAlgs and CMAlgs aerogels were analyzed by the Fourier transform infrared (FT-IR), X-ray diffraction (XRD), BET, Zeta potential, etc. Possible adsorption mechanisms of MAlgs and CMAlgs aerogels were proposed. In addition, the effects of solution $\mathrm{pH}$ and solid-liquid ratio of MAlgs and CMAlgs aerogels on the removal of tetracycline were evaluated, and the cycling stability.

\section{Materials and Methods}

\subsection{Materials}

All chemicals, eg. sodium alginate (molecular weight: 216.2), $\mathrm{CuCl}_{2} \cdot 2 \mathrm{H}_{2} \mathrm{O}, \mathrm{FeCl}_{3} \cdot 6 \mathrm{H}_{2} \mathrm{O}$, 1,3,5-Benzenetricarboxylic acid (BTC) were purchased from Sinopharm Chemical Reagent Co., Ltd. (Shanghai, China). Tetracycline was purchased from the Chinese Pharmacopoeia (Beijing, China).

\subsection{Preparation of MAlgs and CMAlgs Aerogels}

Synthetic routine of aerogels is shown in Scheme 1. Two g of sodium alginate was dissolved in $100 \mathrm{~mL}$ of deionized water and mechanically stirred to obtain a homogeneous solution. The uniform solution was dropped into $0.10 \mathrm{~mol} \cdot \mathrm{L}^{-1} \mathrm{CuCl}_{2} \cdot 2 \mathrm{H}_{2} \mathrm{O}$ and $0.10 \mathrm{~mol} \cdot \mathrm{L}^{-1} \mathrm{FeCl}_{3} \cdot 6 \mathrm{H}_{2} \mathrm{O}$ solution and cross-linked for $10 \mathrm{~h}$ to obtain Alg- $\mathrm{Cu}$ and AlgFe hydrogels, respectively [39,40]. Similarly, the Alg-Fe-Cu hydrogel can be obtained by replacing the crosslinking solution with a mixture of $0.05 \mathrm{~mol} \cdot \mathrm{L}^{-1} \mathrm{CuCl}_{2} \cdot 2 \mathrm{H}_{2} \mathrm{O}$ and $0.05 \mathrm{~mol} \cdot \mathrm{L}^{-1} \mathrm{FeCl}_{3} \cdot 6 \mathrm{H}_{2} \mathrm{O}$. The hydrogels were washed three times with deionized water to remove uncrosslinked metal ions. Then, the hydrogels were transferred to ethanol solution of $30 \mathrm{mg} \mathrm{mL}^{-1}$ 1,3,5-benzenetricarboxylic acid for $18 \mathrm{~h}$ to obtain MAlg-Fe, MAlg-Cu and MAlg -Fe-Cu hydrogels, respectively. All the prepared hydrogels were washed three times with ethanol and deionized water, and then freeze-dried for $24 \mathrm{~h}$ to obtain MAlg-Fe, MAlg$\mathrm{Cu}$ and MAlg-Fe-Cu aerogels [41]. The MAlg-Fe, MAlg- $\mathrm{Cu}$ and MAlg-Fe-Cu aerogels were pyrolyzed at $500{ }^{\circ} \mathrm{C}$ in $\mathrm{N}_{2}$ atmosphere for $1 \mathrm{~h}$ with a heating rate of $5^{\circ} \mathrm{min}^{-1}$, respectively, to obtain $\mathrm{CMAlg}-\mathrm{Fe}$, CMAlg-Cu, and CMAlg-Fe-Cu aerogels. 


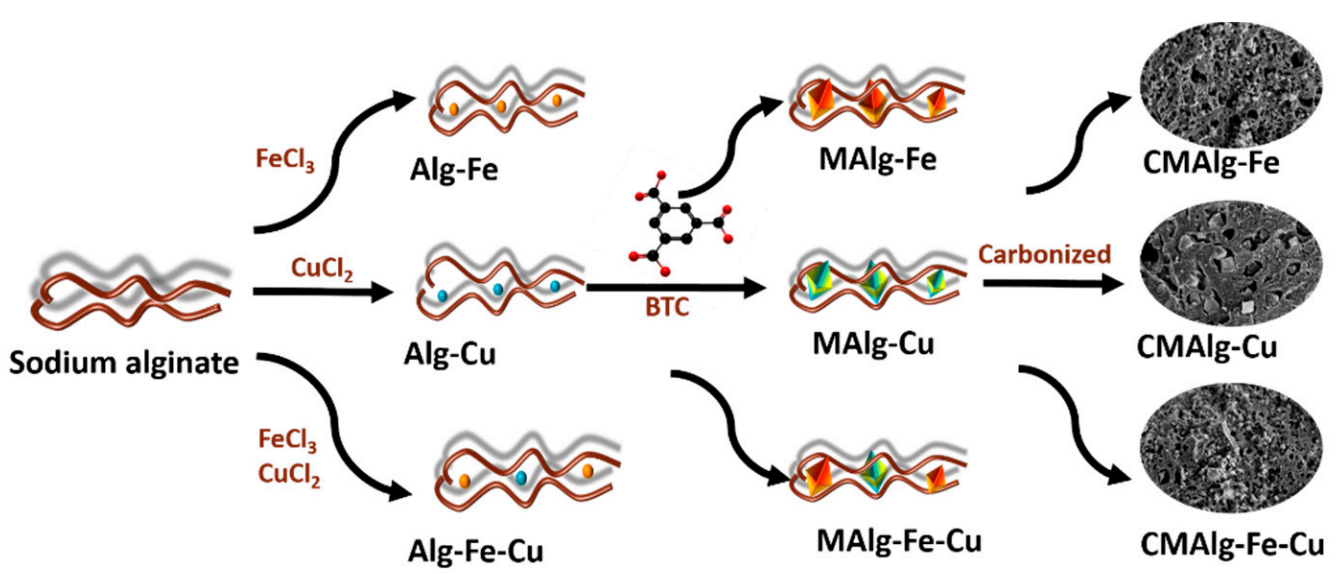

Scheme 1. Synthetic routine of aerogels.

\subsection{Batch Adsorption Experiments}

Batch experiments were conducted to evaluate the performance of MAlgs and CMAlgs aerogels for the adsorption of TC. The isotherm experiments were conducted in a thermostatic shaker at $298 \mathrm{~K}$ and $150 \mathrm{rpm}$ for $480 \mathrm{~min}$ with a solid to liquid ratio of $0.8 \mathrm{~g} \cdot \mathrm{L}^{-1}$ and under varying the initial tetracycline concentrations $\left(20-150 \mathrm{mg} \cdot \mathrm{L}^{-1}\right)$. The kinetics experiments were studied in $150 \mathrm{mg} \cdot \mathrm{L}^{-1} \mathrm{TC}$ solution with a solid to liquid ratio of $0.8 \mathrm{mg} \cdot \mathrm{mL}^{-1}$ under varying reaction time $(5,15,30,60,90,120,180,240,360$, and $480 \mathrm{~min})$. The effects of $\mathrm{pH}$ were studied in $30 \mathrm{mg} \cdot \mathrm{L}^{-1} \mathrm{TC}$ solution with a solid to liquid ratio of $0.8 \mathrm{mg} \cdot \mathrm{mL}^{-1}$ in a $\mathrm{pH}$ range varying from 3 to 11 . The effects of solid to liquid ratio were carried out varying the MAlgs and CMAlgs aerogels dosage from 0.1 to $2 \mathrm{mg} \cdot \mathrm{mL}^{-1}$. The regeneration performance of the aerogel for the adsorption of TC was studied in $30 \mathrm{mg} \cdot \mathrm{L}^{-1} \mathrm{TC}$ solution with a solid to liquid ratio of $0.8 \mathrm{mg} \cdot \mathrm{mL}^{-1}$ and using DMF and methanol solution as the resolving solution. The MAlgs and CMAlgs aerogels were separated from the solution after adsorption and the concentrations of TC were measured at $360 \mathrm{~nm}$ using a UV-vis spectrophotometer (UV-6100, Mapada, Shanghai, China). All the experiments were performed in triplicate and the result selected the numerical average of three results.

Langmuir and Freundlich isotherms were used to evaluate the adsorption equilibrium. The Langmuir and Freundlich isotherm equation is as follows:

$$
\begin{gathered}
\frac{C_{\mathrm{e}}}{q_{\mathrm{e}}}=\frac{1}{K_{\mathrm{L}} q_{\mathrm{m}}}+\frac{C_{\varepsilon}}{q_{\mathrm{m}}} \\
\ln q_{\mathrm{e}}=\ln K_{\mathrm{F}}+\frac{1}{n} \ln C_{\mathrm{e}}
\end{gathered}
$$

where $C_{\mathrm{e}}\left(\mathrm{mg} \cdot \mathrm{L}^{-1}\right)$ is the equilibrium TC concentration in the solution, $q_{\mathrm{m}}\left(\mathrm{mg} \mathrm{g}^{-1}\right)$ is the monolayer adsorption capacity and $K_{\mathrm{L}}\left(\mathrm{L} \cdot \mathrm{mg}^{-1}\right)$ is the Langmuir constant. $K_{\mathrm{F}}$ and $n$ are Freundlich constants.

Pseudo-first-order and pseudo-second-order to evaluate the adsorption process, which is based on solid phase adsorption. These two models can be expressed by Equations (3) and (4), respectively.

$$
\begin{gathered}
\lg \left(q_{\mathrm{e}}-q_{t}\right)=\lg q_{\mathrm{e}}-k_{1} t \\
\frac{t}{q_{t}}=\frac{1}{k_{2} q_{\mathrm{e}}^{2}}+\frac{t}{q_{\mathrm{e}}}
\end{gathered}
$$

where $q_{t}\left(\mathrm{mg} \cdot \mathrm{g}^{-1}\right)$ and $q_{\mathrm{e}}\left(\mathrm{mg} \cdot \mathrm{g}^{-1}\right)$ are the amounts of TC adsorbed at any time and equilibrium, respectively. $k_{1}\left(\mathrm{~min}^{-1}\right)$ and $k_{2}\left(\mathrm{~min}^{-1}\right)$ are the rate constants of pseudo first-order and pseudo second-order, respectively. 


\section{Results}

\subsection{Syntheses and Material Characterization of the Adsorbent}

\subsubsection{Morphological Characterization}

Sodium alginate is a natural linear polysaccharide obtained from brown algae, which has unique gel properties. The $\mathrm{Fe}^{3+}, \mathrm{Cu}^{2+}$ metal ions can independently ion-exchange $\mathrm{Na}^{+}$ in sodium alginate and chelate with alginate chain to produce Alg-Fe and Alg-Cu hydrogel with a "egg-box" structure. Alginate chains can also simultaneously chelate $\mathrm{Fe}^{3+}$ and $\mathrm{Cu}^{2+}$ alginate chains to produce AlG-Fe-Cu hydrogel. Subsequently, the hydrogel spheres as mentioned above are dispersed in an ethanol solution of organic ligand trimellitic acid to obtain MAlgs (MAlg-Fe, MAlg-Cu, and MAlg-Fe-Cu) hydrogel spheres with uniformly dispersed internal MOFs crystal particles. This is mainly because the metal ions are anchored in the three-dimensional network through the coordination of COO- related to guluronic acid on the alginate chain, which facilitates the further coordination of the anchored metal ions with the organic ligands to form crystal in situ. CMAlgs (CMAlg$\mathrm{Fe}, \mathrm{CMAlg}-\mathrm{Cu}$, and $\mathrm{CMAlg}-\mathrm{Fe}-\mathrm{Cu}$ ) aerogel with multilayer pore structure was obtained by thermal decomposition based on MAlgs aerogel of in-situ grown MOFs materials as templates.

The microstructure images of MAlgs aerogel and CMAlgs aerogel were obtained by SEM. As shown in Figure 1, MAlg aerogel presents an interconnected three-dimensional network structure and the MOFs particles contained therein exhibit good dispersibility, which further proves that the three-dimensional network structure can effectively limit the growth and aggregation of MOF particles. Different central metal ions in MAlgs gel lead to different morphologies and structures of MAlg-Fe and MAlg-Cu, MAlg-Fe-Cu aerogels. The MAlg-Fe aerogel shows a honeycomb-like 3D network structure with MOFs particles grown in its grid. The MAlg-Cu aerogel is covered with MOFs particles on its flat gel matrix. The MAlg-Fe-Cu aerogel has an uneven surface due to the growth of MOFs particles. The three-dimensional network structure is still maintained after pyrolysis. The polycondensation of the metal-organic framework leads to the formation of micropores between metal particles and the alginate framework. However, it was obviously observed that the porosity of CMAlg-Cu aerogel was lower than that of CMAlg-Cu and CMAlgFe- $\mathrm{Cu}$ aerogels. The decomposition and collapse of the alginate gel framework and the etching of the metal particles are favorable for the formation of mesoporous structures. The multilayer pore structure is beneficial to the adsorption of pollutants.
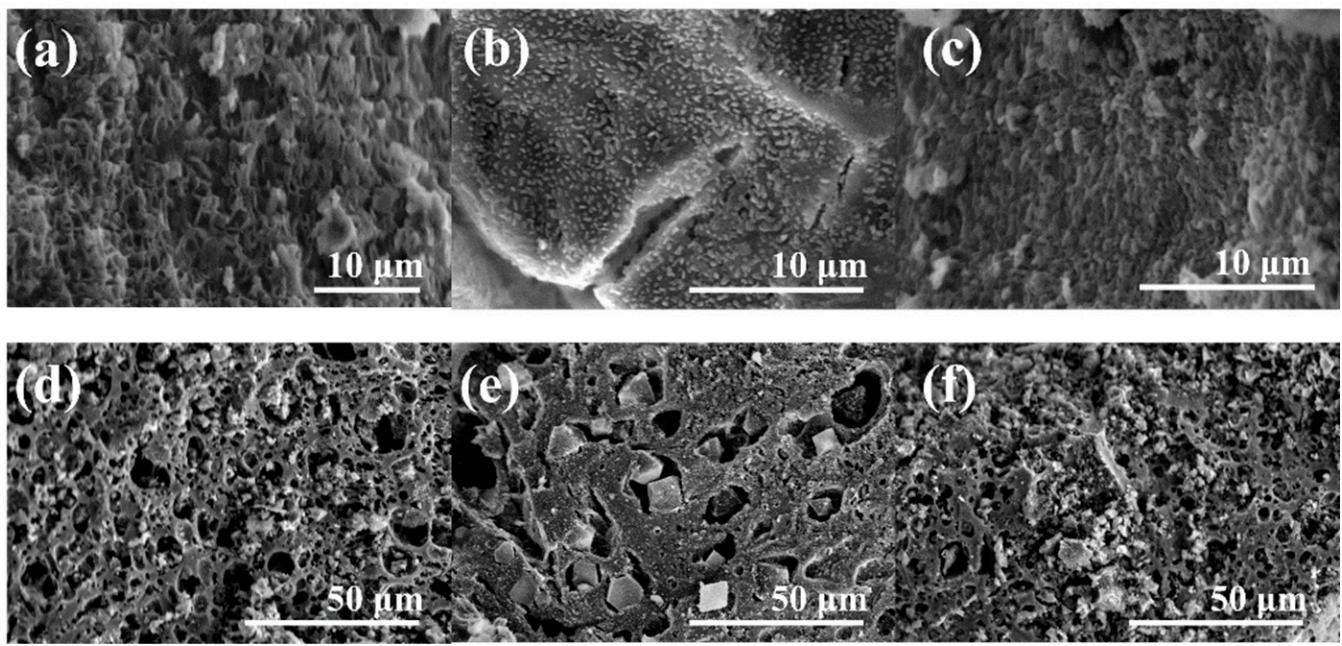

Figure 1. SEM microphotographs of (a) MAlg-Fe, (b) MAlg-Cu, (c) MAlg-Fe-Cu, (d) CMAlg-Fe, (e) CMAlg-Cu, and (f) CMAlg-Fe-Cu aerogels. 


\subsubsection{FTIR and XRD Analysis}

The crystal phase and structure of the sample were analyzed by XRD pattern, as shown in Figure 2a. The XRD peaks of the synthesized MAlg-Fe aerogel have diffraction peaks of certain intensity at $2 \theta=10.3^{\circ}$ and $20.1^{\circ}$, which are similar to the characteristic peaks in the XRD spectrum of MIL-100 (Fe) reported in the literature [42,43]. The broadening of the main diffraction peaks is mainly due to the three-dimensional pores of the gel network restricting crystal growth, resulting in high dispersion and small particle size of MIL-100 $(\mathrm{Fe})$ crystals. The diffraction peaks of MAlg-Cu aerogel are in good agreement with the standard spectrum of HKUST-1, which confirms that HKUST-1 crystals are successfully deposited in situ in MAlg-Cu aerogel [44-46]. For the MAlg-Fe-Cu aerogel, the diffraction peaks are broadened, and the degree of crystallinity is poor. CMAlg-Fe aerogel has a diffraction peak of nano-zero-valent iron at $43.1^{\circ}$, which confirms that metal particles can be reduced to $\mathrm{Fe}^{0}$ after carbonization with alginate and MOF as template materials. In addition, $\mathrm{Fe}_{3} \mathrm{O}_{4}$ characteristic diffraction peaks appear at $2 \theta=30.1^{\circ}, 35.4^{\circ}, 57.6^{\circ}$ and $62.5^{\circ}$, which is speculated to be caused by the presence of organic ligands and oxygen-containing groups in alginate. The XRD diffraction peaks at $2 \theta=43.3^{\circ}, 50.6^{\circ}$ and $74.2^{\circ}$ of $\mathrm{CMAlg}-\mathrm{Cu}$ are distributed to the (111), (200) and (220) planes of $\mathrm{Cu}^{0}$, indicating that the copper ions in the MAlg-Cu aerogel structure are reduced to copper particles during the carbonization process. For CMAlg-Fe- $\mathrm{Cu}$ aerogel, the XRD diffraction peaks at $2 \theta=18.3^{\circ}, 30.1^{\circ}, 35.4^{\circ}$, $43.0^{\circ}, 56.9^{\circ}$, and $62.5^{\circ}$ are distributed to the (111), (220), (311), (400), (511), and (440) planes of cuprospinel $\left(\mathrm{Cu}_{0.86} \mathrm{Fe}_{2.14} \mathrm{O}_{4}\right)$.
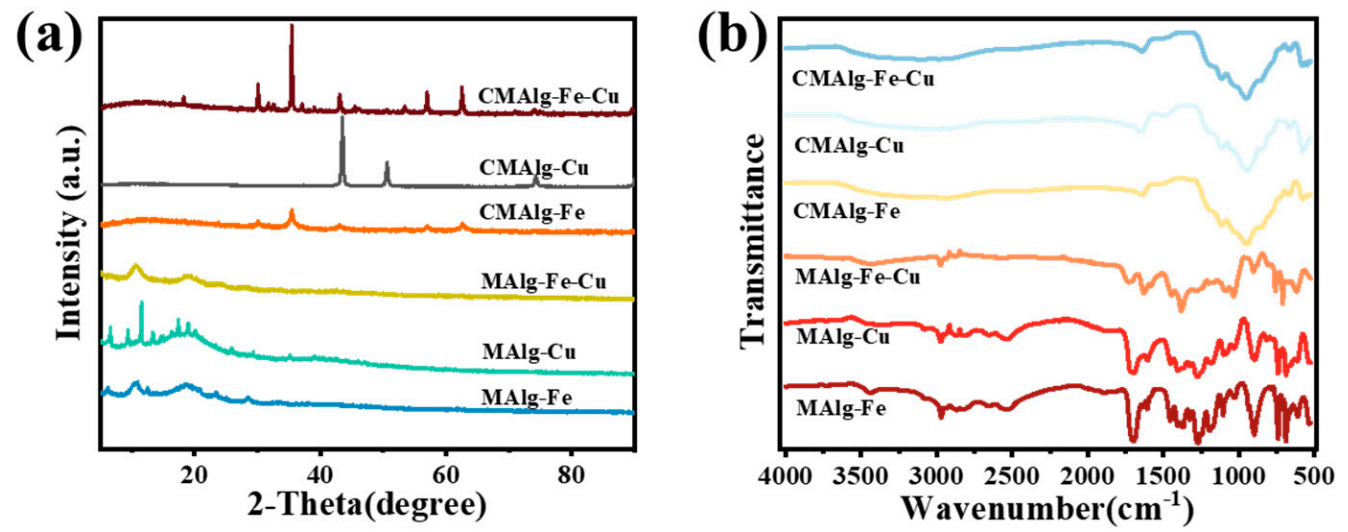

Figure 2. (a) XRD spectra of MAlgs and CMAlgs aerogels, (b) FTIR spectra of MAlgs and CMAlgs aerogels.

The FTIR spectra of the MAlgs aerogel before and after carbonization are shown in Figure $2 \mathrm{~b}$. The peaks at 1629, 1451, and $1364 \mathrm{~cm}^{-1}$ in MAlgs aerogel are attributed to the stretching vibration peak of $\mathrm{C}=\mathrm{O}$, the flexural vibration peak of the hydroxyl group, and the stretching vibration peak $\mathrm{C}-\mathrm{O}$, respectively. For MAlgs aerogels, the peak at $711 \mathrm{~cm}^{-1}$ is the fingerprint peak of MIL-100 (Fe), which is attributed to the $\mathrm{Fe}_{3} \mathrm{O}$ structure, and $742 \mathrm{~cm}^{-1}$ is attributed to the stretching vibration peak of the $\mathrm{Cu}-\mathrm{O}$ bond coordinated by $\mathrm{Cu}$ and BTC. For the increased aromatic structure of CMAlgs aerogel after carbonization, the peak at $2951 \mathrm{~cm}^{-1}$ is attributed to the stretching vibration of $\mathrm{C}-\mathrm{H}$, and at $930 \mathrm{~cm}^{-1}$ is attributed to the $\mathrm{C}-\mathrm{O}-\mathrm{C}$ stretching vibration. It is found that carbonization still retains a large number of oxygen-containing functional groups $(-\mathrm{CO},-\mathrm{COO}, \mathrm{C}=\mathrm{O})$, which can improve the hydrophilicity between the adsorbent surface and the adsorption interface, making the adsorption process smoother.

\subsubsection{The BET Surface Areas and Pore Volumes Analysis}

The pore structure of MAlg aerogel before and after carbonization was analyzed by nitrogen adsorption-desorption test, as shown in the Figure 3a. Obvious hysteresis loops can be observed on the adsorption-desorption curves of MAlgs aerogel and CMAlgs aerogel, which belong to type IV curve, proving that the aerogel contains abundant mesoporous 
pores. The specific surface areas of MAlg-Fe, MAlg-Cu, MAlg-Fe-Cu, CAlg-Fe-Cu are $375.37,258.33,685.56$, and $329.51 \mathrm{~m}^{2} \mathrm{~g}^{-1}$, respectively. It is found that the specific surface area decreased after carbonization, which may be caused by the decomposition of threedimensional network skeleton and the condensation of metal-organic ligands.

(a)

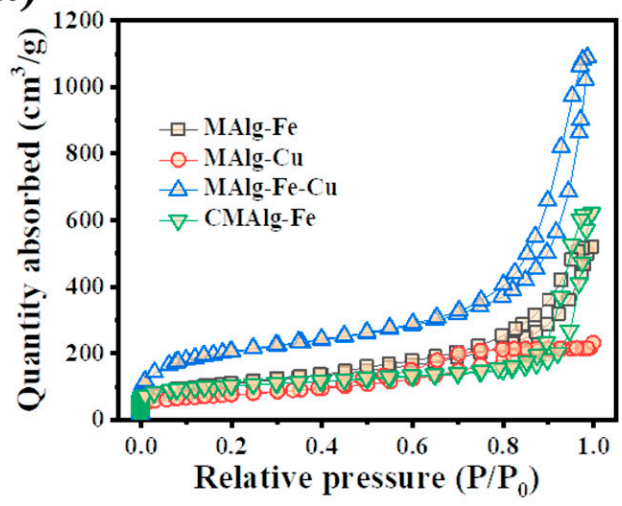

(b)

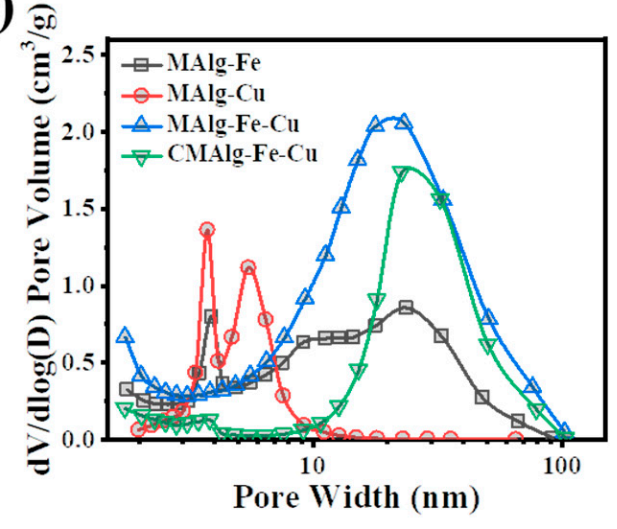

Figure 3. (a) $\mathrm{N}_{2}$ adsorption-desorption isotherms (b) pore size distributions of aerogels.

As shown in Figure 3b, the sample single metal MAlgs shows mesoporous size distribution, and the center is in the range of 4-11 nm with an obvious peak. The pore structure of bimetal MAlG-Fe-Cu is concentrated in the range of $10-100 \mathrm{~nm}$. The pore structure of CMAlg-Fe-Cu after carbonization becomes larger, which is consistent with the results of SEM. The prepared aerogel's mesoporous and three-dimensional macroporous structure is conducive to exposing more adsorption sites and the unobstructed pore structure is conducive to reducing the mass transfer resistance of pollutants.

\subsubsection{The Raman and Pore VSM Analysis}

The Raman test was performed on the aerogel CMAlg aerogel obtained by pyrolysis, as shown in Figure 4a. Two resonance peaks were observed at $1350 \mathrm{~cm}^{-1}$ (peak D) and $1580 \mathrm{~cm}^{-1}$ (peak G), which were attributed to graphitized $s p^{2}$ carbon and disordered $s p^{3}$ carbon, respectively. The degree of defects of carbon materials is measured according to the intensity ratio of peak $\mathrm{D}$ to peak $\mathrm{G}\left(I_{\mathrm{D}} / I_{\mathrm{G}}\right)$. The results show that the $I_{\mathrm{D}} / I_{\mathrm{G}}$ of CMAlg-Fe, CMAlg-Cu, and CMAlg-Fe-Cu aerogels are $0.84,0.82$, and 0.83 , respectively. This indicates that iron is more likely to make carbon materials highly disordered and can produce more defects, which is conducive to the exposure of adsorption sites, thereby improving the adsorption performance of aerogels.
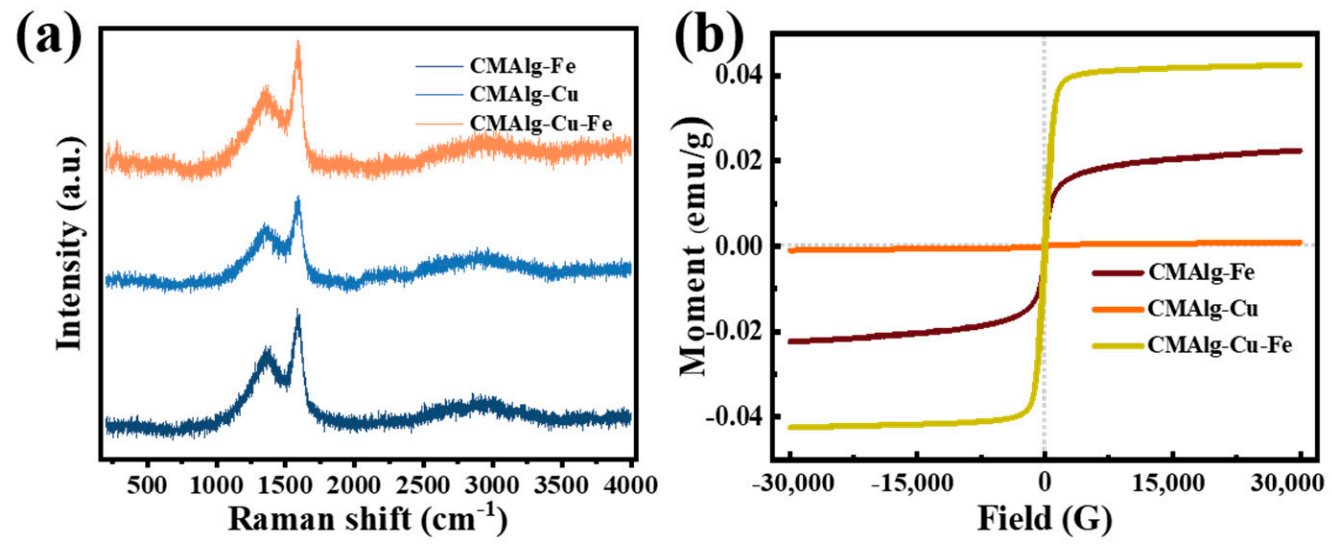

Figure 4. (a) Raman spectra of CMAlgs aerogels, (b) VSM of CMAlgs aerogels.

CMAlg aerogel has certain magnetic properties due to the inclusion of $\mathrm{Fe}^{0}$ and $\mathrm{Cu}^{0}$. The saturation magnetic field intensity was tested. As shown in Figure 1, the saturation 
magnetization of CMALG-Fe and CMALG-Fe-Cu aerogels were 0.02 and $0.04 \mathrm{emu} \mathrm{g}^{-1}$ respectively, showing weak magnetic properties on the CMAlgs aerogel surface.

\subsection{Batch Adsorption Studies}

\subsubsection{Adsorption Isotherm Models}

The adsorption processes of MAlgs and CMAlgs aerogels were fitted with Langmuir and Freundlich models, respectively. Both the Langmuir and Freundlich models can fit the experimental data well, and the Freundlich model has a better fit $\left(R^{2}>0.99\right)$.

The results showed that the uneven surface of aerogel could form adsorption active sites with different energy. The adsorption process of MAlgs and CMAlgs aerogels consists mainly of multilayer physical interaction and monolayer chemical complexation. Figure 5 and Table 1 show that the maximum adsorption capacity of MAlg-Fe, MAlg- $\mathrm{Cu}$, and MAlg-Fe-Cu aerogels are 128.37, 108.23 and $130.72 \mathrm{mg} \cdot \mathrm{g}^{-1}$, respectively, among which MAlg-Cu-Fe has the highest adsorption capacity. After carbonization of the prepared aerogels, the maximum adsorption amounts of CMAlg-Fe, CMAlg- $\mathrm{Cu}$, and CMAlg-Fe-Cu aerogels are $106.16,56.66$ and $131.06 \mathrm{mg} \cdot \mathrm{g}^{-1}$, respectively. The adsorption capacity of CMAlg-Fe and CMAlg-Cu decreased significantly, especially for CMAlg-Cu aerogel. The hydroxyl and carboxyl functional groups of alginate in MAlgs aerogels can interact with water through hydrogen bonding and have hydrophilic properties, which facilitate the transport of tetracycline solution and adequate contact with gel adsorption sites in the pore channels of 3D network macropores and mesopores. In addition, the MOF-functionalized MAlgs have a large specific surface area as well as the protonated amino, carboxyl, and hydroxyl groups in the molecular structure of tetracycline can form hydrogen bonds with organic oxygen-containing functional groups on the MAlgs aerogels. CMAlgs aerogel surface has strong aromaticity and few oxygen-containing functional groups. The large specific surface area is still maintained, especially for CMAlg-Fe-Cu. The aromatic structure of CMAlgs can form $\pi-\pi$ stacking interactions with the benzene structure of tetracycline. It can also experience a cation- $\pi$ mechanism with the protonated amino group of tetracycline, which is the main reason for the adsorption of CMAlgs gel. The pores of CMAlg-Cu show inhomogeneity due to carbonization as well as the formation of metal particles leading to the blockage of pore channels and occupying the corresponding active sites. The poor hydrophilicity is not conducive to the mass transfer of tetracycline solution. This means that some internal pores may be ineffective for the adsorption of large tetracyclines. Iron oxides and graphitized carbon mainly dominate CMAlg-Fe-Cu and CMAlg-Fe aerogel aerogels. The literature reports that iron oxides have a potent complexation tetracycline. Hence, their surface adsorption processes include chemical coordination and multilayer physical adsorption processes.
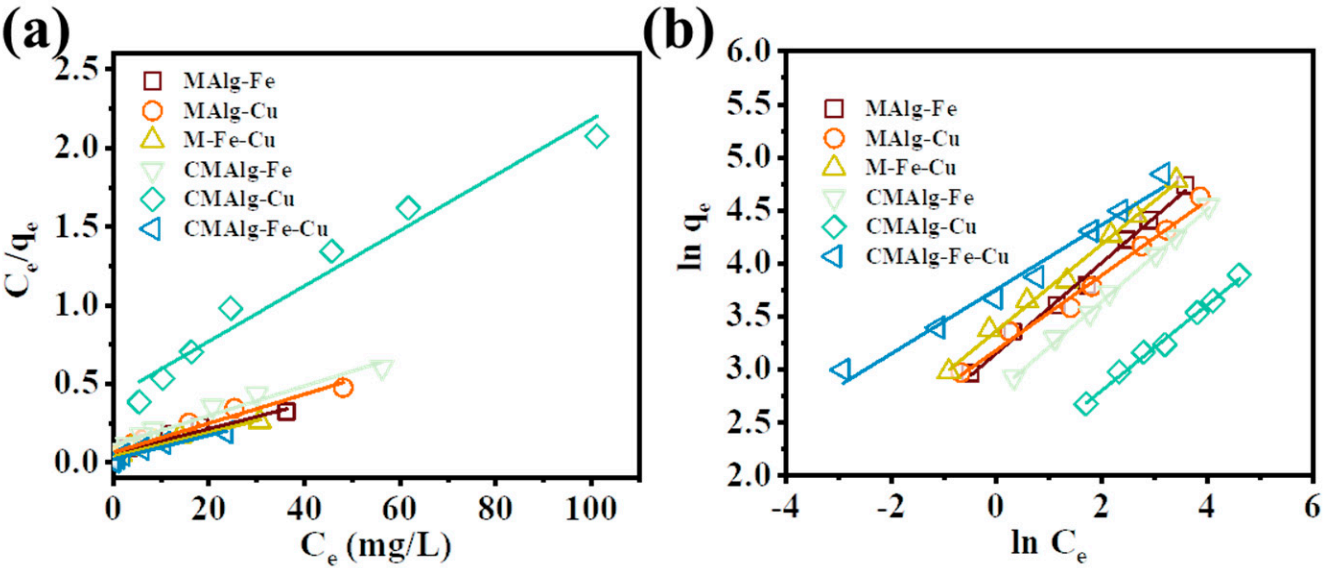

Figure 5. Adsorption isotherm models of (a) Langmuir, (b) Freundlich. 
Table 1. Isotherm parameters of Langmuir, and Freundlich adsorption isotherm.

\begin{tabular}{cccccccc}
\hline Isotherm & \multicolumn{3}{c}{ Langmuir } & \multicolumn{3}{c}{ Freundlich } \\
\hline Characteristic & $\boldsymbol{q}_{\boldsymbol{m}} \mathbf{( \mathbf { m g } / \mathbf { g } )}$ & $\mathbf{K}_{\mathbf{L}}(\mathbf{L} / \mathbf{m g})$ & $\boldsymbol{R}^{\mathbf{2}}$ & $\boldsymbol{R}_{\mathbf{L}}$ & $\mathbf{K}_{\mathbf{F}}(\mathbf{L} / \mathbf{g})$ & $n$ & $\boldsymbol{R}^{\mathbf{2}}$ \\
\hline MAlg-Fe & 128.37 & 0.13 & 0.93 & 0.005 & 23.45 & 2.34 & 0.99 \\
MAlg-Cu & 108.23 & 0.14 & 0.94 & 0.0046 & 24.2 & 2.84 & 0.98 \\
MAlg-Fe-Cu & 130.72 & 0.2 & 0.95 & 0.0033 & 28.98 & 2.45 & 0.99 \\
CMAlg-Fe & 106.16 & 0.09 & 0.95 & 0.0077 & 7.37 & 2.48 & 0.99 \\
CMAlg-Cu & 56.66 & 0.04 & 0.96 & 0.0155 & 16.14 & 2.31 & 1 \\
CMAlg-Fe-Cu & 131.06 & 0.39 & 0.94 & 0.0017 & 42.85 & 3.29 & 0.97 \\
\hline
\end{tabular}

\subsubsection{Adsorption Kinetics}

A kinetic model was used to fit the data to understand the reaction pathway and the adsorption rate of the aerogels. The adsorption of tetracycline by MAlgs and CMAlgs aerogels increased sharply during the first $30 \mathrm{~min}$ of the adsorption process, and then the adsorption process slowed down until it leveled off (Figure 6). At the beginning of the reaction, tetracycline molecules rapidly occupied the abundant active sites on the aerogel surface, and the adsorption amount decreased with time due to the saturation of the active sites as the reaction proceeded. The fitted parameters of the kinetics of tetracycline adsorption by MAlgs and CMAlgs aerogels are shown in Table 2. Both the fitted primary kinetic model and the fitted secondary kinetic model can fit the experimental data well, in which the fitted secondary kinetic model fits better $\left(R^{2}>0.99\right)$. Meanwhile, the amount of tetracycline adsorption by aerogels obtained from the fitted secondary kinetic equation is closer to the actual adsorption amount. Among the adsorption processes that control the adsorption rate are chemisorption processes accompanied by physical adsorption. Studies have shown that the faster adsorption rate of CMAlg-Fe-Cu aerogel is due to its ability to provide more mesopore volumes and more adsorption sites.

(a)

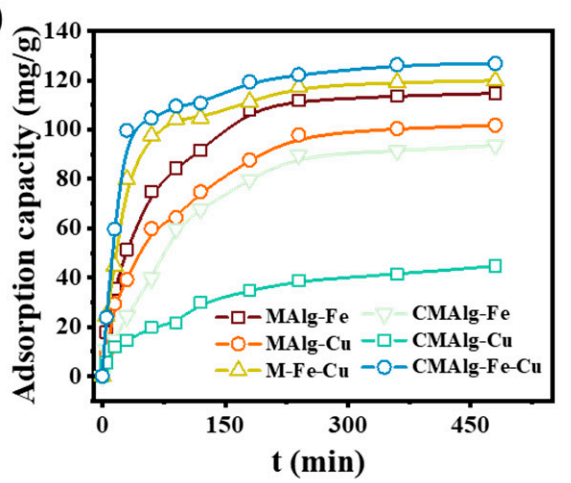

(b)

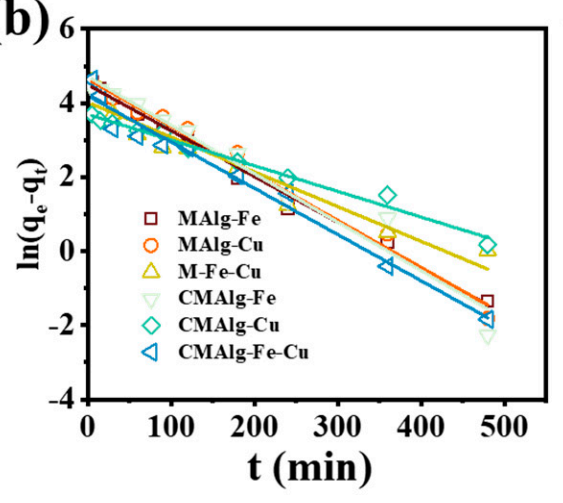

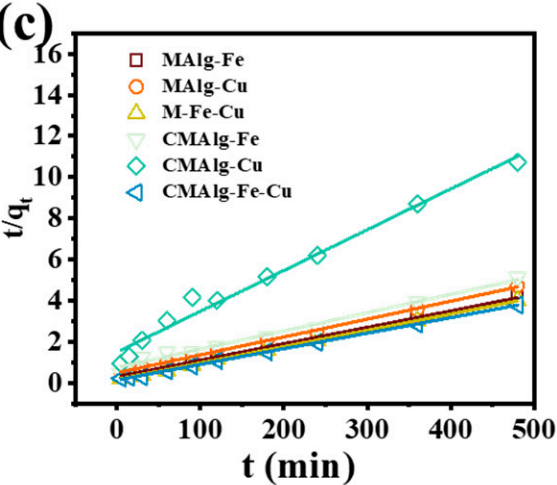

Figure 6. (a) Kinetic curves, (b) pseudo-first-order model, (c) pseudo-second-order model of TC adsorption on aerogels.

\subsubsection{Effect of Solid-Liquid Ratio}

The effect of solid-liquid ratio on the removal of tetracycline by MAlgs and CMAlgs aerogels is shown in Figure 7. The solid-liquid ratio was set to increase from $0.1 \mathrm{~g} \cdot \mathrm{L}^{-1}$ to $2 \mathrm{~g} \cdot \mathrm{L}^{-1}$. The removal efficiency of MAlg-Fe-Cu and CMAlg-Fe-Cu aerogels had reached $\sim 90 \%$ when the addition amount was $0.5 \mathrm{~g} \cdot \mathrm{L}^{-1}$, and then gradually increased and leveled off. However, the adsorption capacity of the MAlg-Fe-Cu and CMAlg-Fe-Cu aerogels showed a decreasing trend. It is attributed to the fact that tetracycline molecules quickly occupied the adsorption site at the MAlg-Fe- $\mathrm{Cu}$ and CMAlg-Fe- $\mathrm{Cu}$ aerogels surface. Then the adsorption site was gradually saturated, and the system tended to be in equilibrium. The higher removal efficiency is caused by the increase of total surface functional groups and effective contact area. Excessive addition of aerogel leads to the decrease of adsorption capacity because the overlap of active sites reduces the effective contact area of tetracycline 
and causes waste of adsorbent. $0.8 \mathrm{~g} \cdot \mathrm{L}^{-1}$ was selected as the most suitable solid-liquid ratio in consideration of removal efficiency and economy.

Table 2. Kinetic parameters of the pseudo-first-order and pseudo-second-order adsorption kinetic models.

\begin{tabular}{ccccccc}
\hline & \multicolumn{3}{c}{ Pseudo-First-Order } & \multicolumn{3}{c}{ Pseudo-Second-Order } \\
\cline { 2 - 7 } Adsorbent & $\begin{array}{c}\boldsymbol{q}_{\mathbf{e}} \\
\left(\mathbf{m ~ g ~}^{-\mathbf{1}} \mathbf{)}\right.\end{array}$ & $\boldsymbol{k}_{\mathbf{1}}$ & $\boldsymbol{R}^{\mathbf{2}}$ & $\begin{array}{c}\boldsymbol{q}_{\mathrm{e}} \\
\mathbf{( m g / g )}\end{array}$ & $\boldsymbol{k}_{\mathbf{2}} \times \mathbf{1 0}^{-\mathbf{3}}$ & $\boldsymbol{R}^{\mathbf{2}}$ \\
\hline MAlg-Fe & 89.50 & 0.03 & 0.989 & 121.80 & 0.24 & 0.998 \\
MAlg-Cu & 103.81 & 0.03 & 0.984 & 110.99 & 0.18 & 0.997 \\
MAlg-Fe-Cu & 55.78 & 0.02 & 0.929 & 124.69 & 0.41 & 0.999 \\
CMAlg-Fe & 111.36 & 0.03 & 0.959 & 106.16 & 0.13 & 0.990 \\
CMAlg-Cu & 40.19 & 0.02 & 0.982 & 50.58 & 0.26 & 0.990 \\
CMAlg-Fe-Cu & 66.48 & 0.03 & 0.973 & 130.55 & 0.46 & 0.999 \\
\hline
\end{tabular}

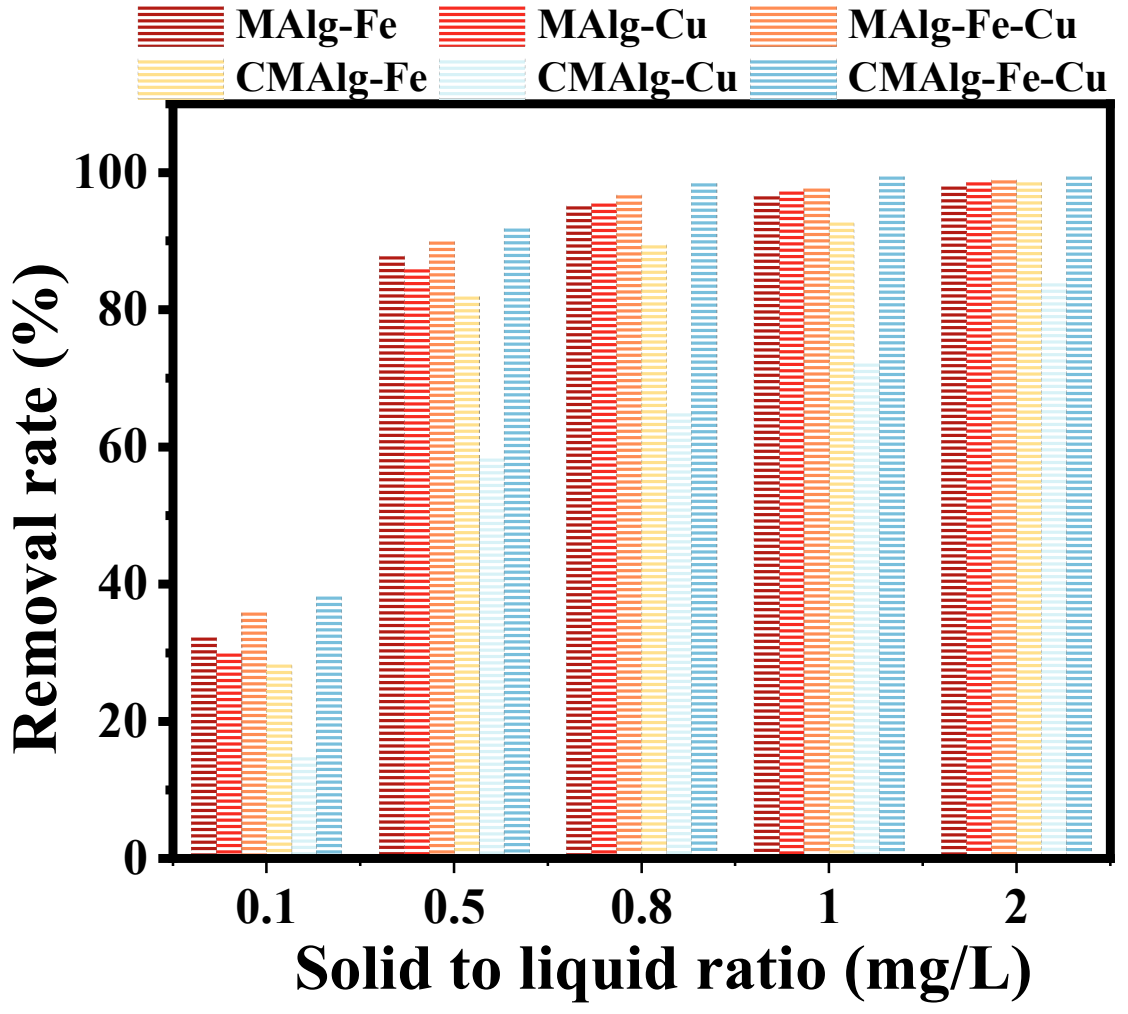

Figure 7. Effect of solid liquid ratio on the removal of tetracycline by MAlgs and CMAlgs aerogels.

\subsubsection{Effect of $\mathrm{pH}$}

It was found that the amount of tetracycline adsorbed by MAlg-Fe- $\mathrm{Cu}$ and $\mathrm{CMAlg}-\mathrm{Fe}-\mathrm{Cu}$ aerogels was significantly $\mathrm{pH}$-dependent. Both $\mathrm{MAlg}-\mathrm{Fe}-\mathrm{Cu}$ and $\mathrm{CMAlg}-\mathrm{Fe}-\mathrm{Cu}$ aerogel adsorption were effective in the range of solution initial $\mathrm{pH}$ from 3 to 11, indicating that the aerogel could remove tetracycline by adsorption over a wide range of $\mathrm{pH}$. When the initial solution $\mathrm{pH}=3$, the removal rate of tetracycline by $\mathrm{MAlg}-\mathrm{Fe}-\mathrm{Cu}$ and $\mathrm{CMAlg}-\mathrm{Fe}-\mathrm{Cu}$ reaches $85.8 \%$ and $89.3 \%$, and the removal effect decreases slightly when the $\mathrm{pH}$ is 11 . The existing form of antibiotics in solution will change with the change of $\mathrm{pH}$. There are three equilibrium constants of tetracycline in aqueous solution: $\mathrm{pKa} 1=3.30, \mathrm{pK}_{\mathrm{a}} 2=7.68$, $\mathrm{pK}_{\mathrm{a}} 3=9.68$. Therefore, it can be dissociated into four different forms at different $\mathrm{pH}$ : cationic form $\left(\mathrm{TC}^{+}\right)$, amphoteric form $\left(\mathrm{TC}^{0}\right)$, anionic form $\left(\mathrm{TC}^{-}\right)$, and the double anion form $\left(\mathrm{TC}^{2-}\right)$. The zeta potentials of MAlg-Fe-Cu and CMAlg-Fe-Cu were further tested under different $\mathrm{pH}$ conditions (Figure 8b). TC completely loses electrons and assumes a cationic form $\left(\mathrm{TC}^{+}\right)$at lower $\mathrm{pH}$, at this time, the MAlg-Fe-Cu and CMAlg-Fe-Cu aerogels showed electronegativity, which was favorable for electrostatic adsorption. The adsorption 
effect of MAlg-Fe-Cu and CMAlg-Fe-Cu aerogels on tetracycline gradually increases with the increase of $\mathrm{pH}$, which was attributed to the enhanced electronegativity of MAlg-Fe- $\mathrm{Cu}$ and $\mathrm{CMAlg}-\mathrm{Fe}-\mathrm{Cu}$ aerogels. When $\mathrm{pH}$ value increases to neutral, TC molecules gradually exist in amphoteric $\mathrm{TC}^{0}$ and the adsorption process lacks electrostatic adsorption. As the $\mathrm{pH}$ continues to increase, the presence of negatively charged forms such as $\mathrm{TC}^{-}$molecule $\mathrm{TC}^{2-}$, however, the negative charge of MAlg-Fe- $\mathrm{Cu}$ and CMAlg-Fe-Cu aerogels reached a maximum electrostatic repulsion, leading to the lowest adsorption. At this time, the adsorption process of aerogels mainly relies on pore filling and $\pi-\pi$ interaction between aromatic structures.
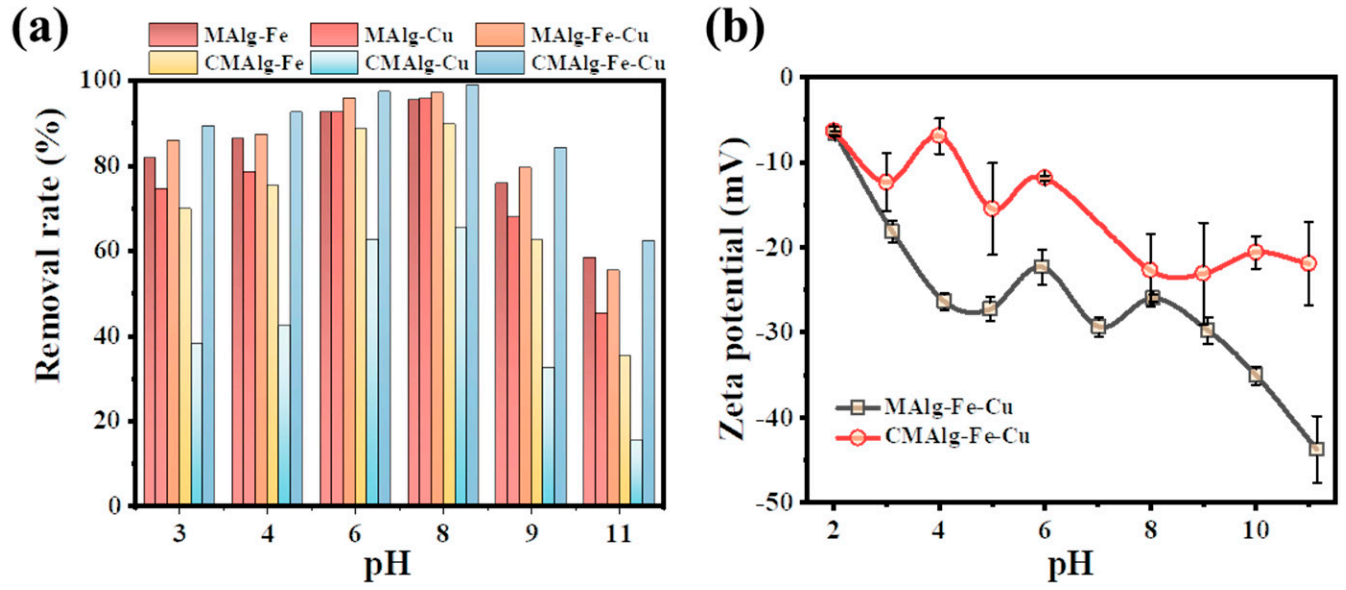

Figure 8. (a) The influence of the $\mathrm{pH}$, (b) Zeta potential of MAlg-Fe-Cu and CMAlg-Fe-Cu aerogels.

\subsubsection{Regenerability}

Reusability is one of the essential criteria to evaluate the performance of adsorbent materials. The regeneration performance of the aerogel for the adsorption of tetracycline was studied using DMF and methanol solution as the resolving solution. The experimental results are shown in Figure 9. The equilibrium adsorption amounts of tetracycline adsorbed by MAlg-Fe-Cu and CMAlg-Fe-Cu aerogels are lost about $22 \%$ and $8 \%$ after six regeneration cycles by resolution, respectively. The main reason is that the adsorption capacity of the MAlg-Fe-Cu aerogel is reduced because the binding sites of the MOF backbone in the $\mathrm{MAlg}-\mathrm{Fe}-\mathrm{Cu}$ aerogel are destroyed during the desorption and recycling process. However, CMAlg-Fe-Cu aerogel has excellent stability and good regeneration performance, which is a selective adsorption material with good application prospects.

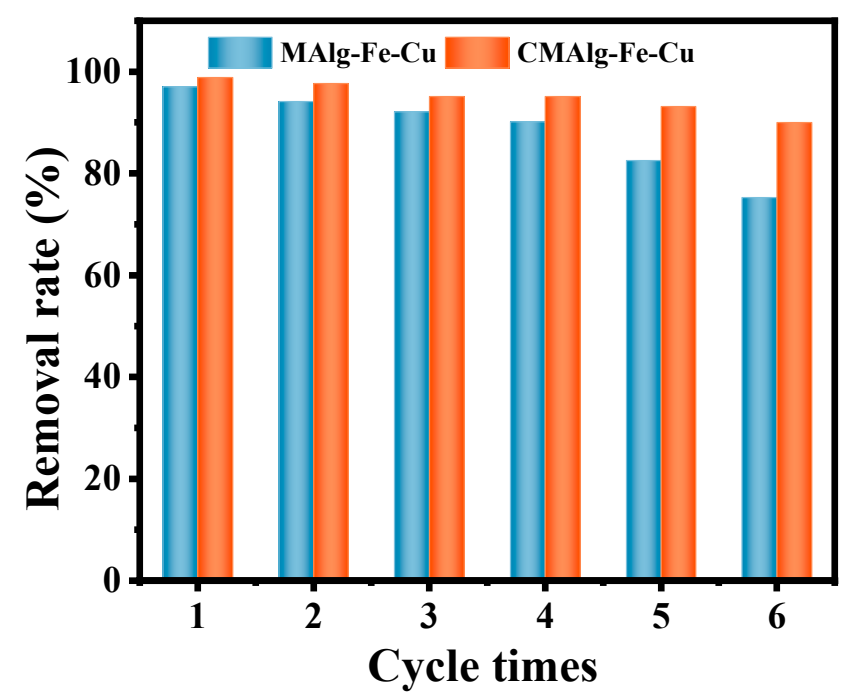

Figure 9. Adsorption cycles of TC by MAlg-Fe-Cu and CMAlg-Fe-Cu aerogels. 


\section{Conclusions}

In summary, a series of functionalized MAlgs and CMAlgs aerogels were synthesized by simple in-situ growth and pyrolysis to solve environmental problems. The threedimensional network of MAlgs aerogel can grow MOFs particles well and effectively prevent aggregation, presenting a mesoporous structure. CMAlg-Cu aerogels have ineffective tetracycline adsorption due to the smaller shrinkage pore size after carbonization. In addition, CMAlgs aerogels exhibit weak magnetic properties. The maximum adsorption capacity of MAlgs and CMAlgs aerogels for tetracycline is $\sim 130 \mathrm{mg} \cdot \mathrm{g}^{-1}$, respectively. The results of adsorption kinetics and adsorption isotherms indicate that adsorption process can be combined with physical adsorption and chemical adsorption and that the surface of the adsorbent is uneven. The adsorption mechanism shows that the adsorption process is dominated by $\pi-\pi$ interaction and pore filling effect. The electrostatic adsorption enhances the adsorption process of aerogel because aerogel is negatively charged under acidic $\mathrm{pH}$. In addition, CMAlgs aerogel exhibits better recyclability than MAlgs aerogel. This study is expected to provide a feasible strategy for removing tetracycline antibiotics and broaden the application range of carbon aerogels as adsorbents.

Author Contributions: Conceptualization, methodology, validation, formal analysis, investigation, data curation, writing-original draft preparation, Y.K. and Y.Z.; writing-review and editing, visualization, K.H.; supervision, project administration, funding acquisition, B.S. All authors have read and agreed to the published version of the manuscript.

Funding: This research was funded by the National Natural Science Foundation of China, grant number 51808538 .

Institutional Review Board Statement: No applicable.

Informed Consent Statement: No applicable.

Data Availability Statement: No applicable.

Conflicts of Interest: The authors declare no conflict of interest.

\section{References}

1. Carballa, M.; Omil, F.; Lema, J.M.; Llompart, M.; García-Jares, C.; Rodríguez, I.; Gómez, M.; Ternes, T. Behavior of pharmaceuticals, cosmetics and hormones in a sewage treatment plant. Water Res. 2004, 38, 2918-2926. [CrossRef]

2. Michael, I.; Rizzo, L.; McArdell, C.S.; Manaia, C.M.; Merlin, C.; Schwartz, T.; Dagot, C.; Fatta-Kassinos, D. Urban wastewater treatment plants as hotspots for the release of antibiotics in the environment: A review. Water Res. 2013, 47, 957-995. [CrossRef] [PubMed]

3. Raza, S.; Shin, H.; Hur, H.G.; Unno, T. Higher abundance of core antimicrobial resistant genes in effluent from wastewater treatment plants. Water Res. 2022, 208, 117882. [CrossRef] [PubMed]

4. Liu, H.; Zhou, X.; Huang, H.; Zhang, J. Prevalence of antibiotic resistance genes and their association with antibiotics in a wastewater treatment plant: Process distribution and analysis. Water 2019, 11, 2495. [CrossRef]

5. Ohore, O.E.; Qin, Z.; Sanganyado, E.; Wang, Y.; Jiao, X.; Liu, W.; Wang, Z. Ecological impact of antibiotics on bioremediation performance of constructed wetlands: Microbial and plant dynamics, and potential antibiotic resistance genes hotspots. J. Hazard. Mater. 2022, 424, 127495. [CrossRef]

6. Syranidou, E.; Kalogerakis, N. Interactions of microplastics, antibiotics and antibiotic resistant genes within WWTPs. Sci. Total Environ. 2022, 804, 150141. [CrossRef]

7. Harrower, J.; McNaughtan, M.; Hunter, C.; Hough, R.; Zhang, Z.; Helwig, K. Chemical Fate and Partitioning Behavior of Antibiotics in the Aquatic Environment-A Review. Environ. Toxicol. Chem. 2021, 40, 3275-3298. [CrossRef] [PubMed]

8. Rivera-Utrilla, J.; Sánchez-Polo, M.; Ferro-García, M.Á.; Prados-Joya, G.; Ocampo-Pérez, R. Pharmaceuticals as emerging contaminants and their removal from water. A review. Chemosphere 2013, 93, 1268-1287. [CrossRef] [PubMed]

9. Homem, V.; Santos, L. Degradation and removal methods of antibiotics from aqueous matrices-A review. J. Environ. Manag. 2011, 92, 2304-2347. [CrossRef] [PubMed]

10. Chen, C.; Ma, T.; Shang, Y.; Gao, B.; Jin, B.; Dan, H.; Li, Q.; Yue, Q.; Li, Y.; Wang, Y.; et al. In-situ pyrolysis of Enteromorpha as carbocatalyst for catalytic removal of organic contaminants: Considering the intrinsic N/Fe in Enteromorpha and non-radical reaction. Appl. Catal. B Environ. 2019, 250, 382-395. [CrossRef]

11. Polak, D.; Zielińska, I.; Szwast, M.; Kogut, I.; Małolepszy, A. Modification of ceramic membranes with carbon compounds for pharmaceutical substances removal from water in a filtration-Adsorption system. Membranes 2021, 11, 481. [CrossRef] [PubMed] 
12. Dutta, J.; Mala, A.A. Removal of antibiotic from the water environment by the adsorption technologies: A review. Water Sci. Technol. 2020, 82, 401-426. [CrossRef]

13. Zhi, D.; Yang, D.; Zheng, Y.; Yang, Y.; He, Y.; Luo, L.; Zhou, Y. Current progress in the adsorption, transport and biodegradation of antibiotics in soil. J. Environ. Manag. 2019, 251, 109598. [CrossRef] [PubMed]

14. Karimi-Maleh, H.; Ayati, A.; Davoodi, R.; Tanhaei, B.; Karimi, F.; Malekmohammadi, S.; Orooji, Y.; Fu, L.; Sillanpää, M. Recent advances in using of chitosan-based adsorbents for removal of pharmaceutical contaminants: A review. J. Clean. Prod. 2021, 291, 125880. [CrossRef]

15. Eniola, J.O.; Kumar, R.; Barakat, M.A. Adsorptive removal of antibiotics from water over natural and modified adsorbents Environ. Sci. Pollut. Res. 2019, 26, 34775-34788. [CrossRef] [PubMed]

16. Xiang, Y.; Xu, Z.; Wei, Y.; Zhou, Y.; Yang, X.; Yang, Y.; Yang, J.; Zhang, J.; Luo, L.; Zhou, Z. Carbon-based materials as adsorbent for antibiotics removal: Mechanisms and influencing factors. J. Environ. Manag. 2019, 237, 128-138. [CrossRef]

17. Peng, H.; Xiong, W.; Yang, Z.; Cao, J.; Jia, M.; Xiang, Y.; Hu, Q.; Xu, Z. Facile fabrication of three-dimensional hierarchical porous ZIF-L/gelatin aerogel: Highly efficient adsorbent with excellent recyclability towards antibiotics. Chem. Eng. J. 2021, 426, 130798. [CrossRef]

18. Amaly, N.; EL-Moghazy, A.Y.; Nitin, N.; Sun, G.; Pandey, P.K. Synergistic adsorption-photocatalytic degradation of tetracycline by microcrystalline cellulose composite aerogel dopped with montmorillonite hosted methylene blue. Chem. Eng. J. 2022, $430,133077$. [CrossRef]

19. Jiao, C.; Xiong, J.; Tao, J.; Xu, S.; Zhang, D.; Lin, H.; Chen, Y. International Journal of Biological Macromolecules Sodium alginate/graphene oxide aerogel with enhanced strength-toughness and its heavy metal adsorption study. Int. J. Biol. Macromol. 2016, 83, 133-141. [CrossRef] [PubMed]

20. Feng, J.; Ding, H.; Yang, G.; Wang, R.; Li, S.; Liao, J.; Li, Z.; Chen, D. Preparation of black-pearl reduced graphene oxide-sodium alginate hydrogel microspheres for adsorbing organic pollutants. J. Colloid Interface Sci. 2017, 508, 387-395. [CrossRef]

21. Algothmi, W.M.; Bandaru, N.M.; Yu, Y.; Shapter, J.G.; Ellis, A. V Alginate-graphene oxide hybrid gel beads: An efficient copper adsorbent material. J. Colloid Interface Sci. 2013, 397, 32-38. [CrossRef] [PubMed]

22. Platero, E.; Fernandez, M.E.; Bonelli, P.R.; Cukierman, A.L. Graphene oxide/alginate beads as adsorbents: Influence of the load and the drying method on their physicochemical-mechanical properties and adsorptive performance. J. Colloid Interface Sci. 2017, 491, 1-12. [CrossRef]

23. Zhuang, Y.; Yu, F.; Chen, H.; Zheng, J.; Ma, J.; Chen, J. Alginate/graphene double-network nanocomposite hydrogel beads with low-swelling, enhanced mechanical properties, and enhanced adsorption capacity. J. Mater. Chem. A 2016, 4, 10885-10892. [CrossRef]

24. Sun, L.; Fugetsu, B. Graphene oxide captured for green use: Influence on the structures of calcium alginate and macroporous alginic beads and their application to aqueous removal of acridine orange. Chem. Eng. J. 2014, 240, 565-573. [CrossRef]

25. Nie, L.; Liu, C.; Wang, J.; Shuai, Y.; Cui, X.; Liu, L. Effects of surface functionalized graphene oxide on the behavior of sodium alginate. Carbohydr. Polym. 2015, 117, 616-623. [CrossRef] [PubMed]

26. Liu, S.; Li, Y.; Li, L. Enhanced stability and mechanical strength of sodium alginate composite films. Carbohydr. Polym. 2017, 160, 62-70. [CrossRef]

27. Zhao, P.; Yu, F.; Wang, R.; Ma, Y.; Wu, Y. Chemosphere Sodium alginate / graphene oxide hydrogel beads as permeable reactive barrier material for the remediation of cipro fl oxacin-contaminated groundwater. Chemosphere 2018, 200, 612-620. [CrossRef] [PubMed]

28. Zhuang, Y.; Wang, X.; Zhang, L.; Dionysiou, D.D.; Shi, B. Fe-Chelated polymer templated graphene aerogel with enhanced Fenton-like efficiency for water treatment. Environ. Sci. Nano 2019, 6, 3232-3241. [CrossRef]

29. Zhuang, Y.; Wang, X.; Zhang, L.; Dionysiou, D.D.; Kou, Z.; Shi, B. Double-network hydrogel templated FeS/graphene with enhanced PMS activation performance: Considering the effect of the template and iron species. Environ. Sci. Nano 2020, 7 , 817-828. [CrossRef]

30. Zhuang, Y.; Han, B.; Chen, R.; Shi, B. Structural transformation and potential toxicity of iron-based deposits in drinking water distribution systems. Water Res. 2019, 165, 114999. [CrossRef]

31. Kim, H.G.; Choi, K.; Lee, K.; Lee, S.; Jung, K.W.; Choi, J.W. Controlling the structural robustness of zirconium-based metal organic frameworks for efficient adsorption on tetracycline antibiotics. Water 2021, 13, 1869. [CrossRef]

32. Huang, L.; Shen, R.; Shuai, Q. Adsorptive removal of pharmaceuticals from water using metal-organic frameworks: A review. I. Environ. Manag. 2021, 277, 111389. [CrossRef]

33. Tchinsa, A.; Hossain, M.F.; Wang, T.; Zhou, Y. Removal of organic pollutants from aqueous solution using metal organic frameworks (MOFs)-based adsorbents: A review. Chemosphere 2021, 284, 131393. [CrossRef] [PubMed]

34. Chen, G.; He, S.; Shi, G.; Ma, Y.; Ruan, C.; Jin, X.; Chen, Q.; Liu, X.; Dai, H.; Chen, X.; et al. In-situ immobilization of ZIF-67 on wood aerogel for effective removal of tetracycline from water. Chem. Eng. J. 2021, 423, 130184. [CrossRef]

35. Kong, Y.; Zhuang, Y.; Han, K.; Shi, B. Enhanced tetracycline adsorption using alginate-graphene-ZIF67 aerogel. Colloids Surf. A Physicochem. Eng. Asp. 2020, 588, 124360. [CrossRef]

36. Yang, Z.H.; Cao, J.; Chen, Y.P.; Li, X.; Xiong, W.P.; Zhou, Y.Y.; Zhou, C.Y.; Xu, R.; Zhang, Y. Mn-doped zirconium metal-organic framework as an effective adsorbent for removal of tetracycline and $\mathrm{Cr}(\mathrm{VI})$ from aqueous solution. Microporous Mesoporous Mater. 2019, 277, 277-285. [CrossRef] 
37. Tian, N.; Jia, Q.M.; Su, H.Y.; Zhi, Y.F.; Ma, A.H.; Wu, J.; Shan, S.Y. The synthesis of mesostructured NH2-MIL-101(Cr) and kinetic and thermodynamic study in tetracycline aqueous solutions. J. Porous Mater. 2016, 23, 1269-1278. [CrossRef]

38. Xia, J.; Gao, Y.; Yu, G. Tetracycline removal from aqueous solution using zirconium-based metal-organic frameworks (Zr-MOFs) with different pore size and topology: Adsorption isotherm, kinetic and mechanism studies. J. Colloid Interface Sci. 2021, 590, 495-505. [CrossRef] [PubMed]

39. Zhuang, Y.; Kong, Y.; Han, K.; Hao, H.; Shi, B. A physically cross-linked self-healable double-network polymer hydrogel as a framework for nanomaterial. New J. Chem. 2017, 41, 15127-15135. [CrossRef]

40. Kong, Y.; Zhuang, Y.; Shi, B. Tetracycline removal by double-metal-crosslinked alginate/graphene hydrogels through an enhanced Fenton reaction. J. Hazard. Mater. 2020, 382, 121060. [CrossRef]

41. Zhu, H.; Zhang, Q.; Zhu, S. Alginate Hydrogel: A Shapeable and Versatile Platform for in Situ Preparation of Metal-Organic Framework-Polymer Composites. ACS Appl. Mater. Interfaces 2016, 8, 17395-17401. [CrossRef]

42. Yang, C.; Zhu, Y.; Wang, J.; Sun, W.; Yang, L.; Lin, H.; Lv, S. A novel granular MOF composite with dense and ordered MIL-100(Fe) nanoparticles grown on porous alumina: Green synthesis and enhanced adsorption of tetracycline hydrochloride. Chem. Eng. J. 2021, 426, 131724. [CrossRef]

43. Hang, J.; Yi, X.-H.; Wang, C.-C.; Fu, H.; Wang, P.; Zhao, Y. Heterogeneous photo-Fenton degradation toward sulfonamide matrix over magnetic Fe3S4 derived from MIL-100(Fe). J. Hazard. Mater. 2022, 424, 127415. [CrossRef] [PubMed]

44. Wang, Y.; Yang, G.; Guo, H.; Meng, X.; Kong, G.; Kang, Z.; Guillet-Nicolas, R.; Mintova, S. Preparation of HKUST-1/PEI mixed-matrix membranes: Adsorption-diffusion coupling control of small gas molecules. J. Memb. Sci. 2022, 643, 120070. [CrossRef]

45. Zhang, L.; Guo, C.; Chen, T.; Guo, Y.; Hassan, A.; Kou, Y.; Guo, C.; Wang, J. Effects of different defective linkers on the photocatalytic properties of Cu-BTC for overall water decomposition. Appl. Catal. B Environ. 2022, 303, 120888. [CrossRef]

46. Ma, X.; Wang, L.; Wang, H.; Deng, J.; Song, Y.; Li, Q.; Li, X.; Dietrich, A.M. Insights into metal-organic frameworks HKUST-1 adsorption performance for natural organic matter removal from aqueous solution. J. Hazard. Mater. 2022, 424, 126918. [CrossRef] [PubMed] 